\title{
Awareness about the effects of tobacco consumption on oral health and the possibility of smoking behavior among male Saudi schoolchildren
}

\author{
Muhammad Ashraf Nazir ${ }^{1}$, Khalid Almas ${ }^{1}$
}

Correspondence: Dr. Muhammad Ashraf Nazir

Email: manazir@uod.edu.sa

\begin{abstract}
'Department of Preventive Dental Sciences, College of Dentistry, University of Dammam, Dammam, Kingdom of Saudi Arabia
\end{abstract}

\section{ABSTRACT}

Objective: To investigate an association between the awareness about the effects of tobacco consumption on oral health and the likelihood of smoking among male schoolchildren. Materials and Methods: A cross sectional study was conducted using a multistage random sampling technique. The participants (ages 15-19 years) were recruited from male public high schools in Greater Dammam in Saudi Arabia. A pretested questionnaire inquired participants' awareness about the effects of smoking on oral health. SPSS (Released 2013, IBM SPSS Statistics for Windows, Version 22.0. Armonk, NY: IBM Corp) was used to calculate unadjusted and adjusted odds ratio (OR) and 95\% confidence interval (CI). Multiple logistic regression and interaction analyses were performed to identify the factors associated with the probability of smoking behavior among children. Results: More than $69.9 \%(n=277)$ of participants were aware of the adverse effects of tobacco consumption on oral health which included poor oral health, bad taste and breath, periodontal disease, dental caries, oral ulcers, and oral cancers. The odds of smoking were $22 \%-47 \%$ lower among schoolchildren who were aware of the consequences of smoking on oral health than those who were unaware of these complications. The students who believed that smoking can cause oral ulcers and negatively affects oral health had a lower probability of smoking (OR: 0.414; CI: $0.201-0.50)$ and (OR: 0.433; CI: 0.194-0.965), respectively in comparison with those who thought that smoking had no such negative impacts. Conclusions: Schoolchildren with increased awareness of smoking effects on oral health were less likely to smoke. Educating students about the complications of smoking on oral health should be the part of smoking cessation programs and policies.

Key words: Oral health, Saudi Arabia, schoolchildren, smoking cessation, smoking effects

\section{INTRODUCTION}

According to the $\mathrm{WHO}, 6$ million people die because of tobacco smoking and an estimated 600,000 individuals lose their lives due to second-hand smoke globally each year. ${ }^{[1]} \mathrm{A}$ recent study found that smoking is related to about $20 \%$ adult mortality around the

\begin{tabular}{|l|l|}
\hline \multicolumn{2}{|c|}{ Access this article online } \\
\hline Quick Response Code: \\
\hline
\end{tabular}

world. $^{[2]}$ It is projected that smoking will cause the death of 8 million people every year by 2030 and $80 \%$ of these deaths will occur in low- and middle-income countries. ${ }^{[3]}$ Smoking is associated with increased

This is an open access article distributed under the terms of the Creative Commons Attribution-NonCommercial-ShareAlike 3.0 License, which allows others to remix, tweak, and build upon the work non-commercially, as long as the author is credited and the new creations are licensed under the identical terms.

For reprints contact: reprints@medknow.com

How to cite this article: Nazir MA, Almas K. Awareness about the effects of tobacco consumption on oral health and the possibility of smoking behavior among male Saudi schoolchildren. Eur J Dent 2017;11:29-35.

DOI: 10.4103/ejd.ejd_300_16 
the risk of cardiovascular and chronic respiratory diseases, stroke, and cancers of many organs of the body such as mouth, larynx, lungs, kidneys, cervix, and pancreas. ${ }^{[4]}$

There are significant negative impacts of smoking on health-care system and society ${ }^{[5]}$ causing huge direct health-care expenditures and indirect costs in the form of the loss of productivity and income for families. ${ }^{[6]}$ The economic burden of smoking accounts for $15 \%$ of health care costs in developed countries, and $1 \%$ of gross domestic product is consumed for direct health care costs and US $\$ 151$ billion for indirect expenses every year in the United States. ${ }^{[7]}$ Tobacco consumption is alarming in Saudi Arabia as it is ranked fourth worldwide in terms of tobacco sale, and high proportion of males students (32.7\%) smoke in the country. ${ }^{[8]}$

Large body of epidemiological evidence reveals that smoking is related to oral conditions which include periodontal disease, gingival recession, tooth loss, dental caries, staining of teeth, halitosis, benign mucosal conditions, and precancerous and malignant oral lesions. ${ }^{[9]}$ Smokers live approximately 10 years lesser than never smokers, ${ }^{[10]}$ and smoking cessation efforts can reduce $97 \%$ risk of death associated with continuing smoking before the age of 30 years. ${ }^{[11]}$ This underscores the importance of increasing the awareness about the negative consequences of smoking among adolescents so that morbidities, mortalities, and oral and systematic health inequalities resulting from smoking can be prevented at an earlier age.

Adolescents are vulnerable to starting smoking and becoming addicted to nicotine because they go through rapid hormonal and cognitive changes during their adolescence and they are influenced by cultural, social, familial, and behavioral factors. ${ }^{[12]}$ It is estimated that about 5.6 million American adolescents will die prematurely due to diseases caused by smoking. ${ }^{[13]}$ Adolescent smokers are likely to become addicted to nicotine, and about $90 \%$ of adult smokers used to smoke regularly during their adolescence. ${ }^{[14]}$

The factors that lead adolescents to start smoking include advertising of cigarettes, ${ }^{[15]}$ stress, low self-esteem, poor academic performance, and occurrence of smoking among parents and other family members, friends, and staff at school. ${ }^{[16,17]}$ Moreover, research indicates that initiation of smoking is associated with the perception of risks and benefits of smoking ${ }^{[18]}$ It was found that adolescents with low perception about the long term risks related to smoking were 3.64 times more likely to smoke compared with those who had high perception of smoking related risks. ${ }^{[19]}$ However, the question that whether the awareness about the adverse effects of smoking on oral health has any influence on smoking behaviors among schoolchildren was unclear.

Therefore, the aim of the present study was to evaluate an association between the awareness about smoking effects on oral health and probability of smoking among schoolchildren.

\section{MATERIALS AND METHODS}

A cross sectional study design was employed. A list of male public high schools (grade 10-12) was obtained from Ministry of Education Dammam, Saudi Arabia. Sample size of 453 was calculated using total population of male high schools students, ${ }^{[20]} 95 \%$ confidence interval (CI), anticipated frequency of the outcome, and design effect of the study. ${ }^{[21]}$ The study was commenced after obtaining ethical approval from the institution. The questionnaire was developed and pilot tested on 20 students. The questionnaire inquired about the demographic information, smoking habit, family history of smoking, academic grades in previous year, family income, and father's education level. Seven questions were asked about respondents' awareness regarding the effects of smoking on oral health, taste and breath, oral ulcer, oral cancer, dental caries, and periodontal disease.

Multistage random sampling method was used for data collection. First stage of sampling involved random selection of male public high schools in Greater Dammam, Eastern province of Saudi Arabia. Greater Dammam is a metropolitan area in Eastern province that includes Dammam, Al-Khobar and Dhahran cities. Selected schools were approached and their approval was obtained in the second stage. Then classes were randomly chosen from each selected school in third stage, and finally students were randomly selected from each chosen class. The students were informed about purpose and objectives of the study and their right of voluntary participation in the research. Inform consent was obtained before the administration of questionnaire. Partial data have been reported elsewhere. ${ }^{[20]}$

Frequency distributions for study variables were calculated. Univariate analysis was performed using 
Pearson's Chi-square test to calculate unadjusted odds ratio (OR) of various variables with smoking. Multivariate logistic regression analysis calculated ORs after adjusting for other variables. The independent variables were the effects of smoking on oral health, taste, breath, oral ulcers, oral cancers, caries and periodontal disease, and family history of smoking, academic grades, family income, father's education, and smoking was the dependent variable. Interaction or moderation analysis was also performed to evaluate interaction between variables. Finally, backward stepwise logistic regression final model with its best predictive power was created after eliminating independent variables with insignificant coefficients. ${ }^{[22]}$

\section{RESULTS}

Three hundred and ninety-seven respondents completed questionnaires (response rate $=87.6 \%$ ). The majority of students reported having grades above $80 \%$ in the previous academic year and family income of more than SR 14,000 (Equal to US\$3733) per month. Family history of smoking existed among half of the respondents. Most respondents were aware of the adverse effects of smoking on oral health [Table 1].

Table 2 shows unadjusted ORs of various factors with smoking, and it can be seen that students with academic grade above $80 \%$ had lower chances of smoking compared with those who scored $<80 \%$ grades (OR: 0.275; CI: 0.142-0.530). On the other hand, students with family history of smoking were 2.34 times more likely to smoke than those without family history of smoking (OR: 2.342; CI: 1.396-3.928). The students who believed that smoking has adverse effects on oral health had lower odds of smoking in comparison with those who thought that smoking had no negative impact on oral health [Table 2].

Multivariate logistic regression revealed statistically significant associations between academic grade, family history of smoking, belief that smoking causes oral ulcers and negatively affects oral health. Those who considered that smoking causes oral ulcer and affects oral health were less likely to smoke, (OR: 0.414; CI: 0.201-0.50) and (OR: 0.433; CI: 0.194-0.965), respectively [Table 3]. Interaction analysis found no statistically significant interactions between different variables [Table 4].

Backward stepwise logistic regression final model shows similar probability of smoking if children were aware of the smoking consequences on oral health and oral ulcers. Similarly, schoolchildren who

\begin{tabular}{|c|c|}
\hline Variables & Number(N/\%) \\
\hline \multicolumn{2}{|l|}{ Academic grades (\%) } \\
\hline$>80 \%$ & $353(88.9)$ \\
\hline$<80 \%$ & $44(11.1)$ \\
\hline \multicolumn{2}{|l|}{ Family income } \\
\hline Above SR14000 (Equal to US\$ 3733) & $301(75.8)$ \\
\hline Below SR14000 (Equal to US\$3733) & $96(24.2)$ \\
\hline \multicolumn{2}{|l|}{ Father's education } \\
\hline$\geq$ Bachelor degree & $189(47.6)$ \\
\hline$<$ Bachelor degree & $208(52.4)$ \\
\hline Family history of smoking & $203(51.1)$ \\
\hline Smoking negatively affects oral health & $347(87.4)$ \\
\hline Smoking is related to bad taste & $277(69.8)$ \\
\hline Smoking is related to bad breath & $323(81.4)$ \\
\hline Smoking causes oral ulcers & $309(77.8)$ \\
\hline Smoking causes oral cancers & $326(82.1)$ \\
\hline Smoking causes oral dental caries & $295(74.3)$ \\
\hline Smoking causes periodontal disease & $340(85.6)$ \\
\hline
\end{tabular}

\begin{tabular}{|c|c|}
\hline \multirow[t]{2}{*}{ Variables } & Unadjusted Odds Ratio \\
\hline & OR $(95 \% \mathrm{Cl})$ \\
\hline Academic grades (\%) & $0.275(0.142-0.530)^{*}$ \\
\hline \multicolumn{2}{|l|}{$>80$} \\
\hline \multicolumn{2}{|l|}{$<80$} \\
\hline Family income & $1.124(0.627-2.015)$ \\
\hline \multicolumn{2}{|l|}{ Above SR14000 (Equal to US\$3733) } \\
\hline \multicolumn{2}{|l|}{ Below SR14000 (Equal to US\$3733) } \\
\hline Father's education & $0.823(0.503-1.349)$ \\
\hline \multicolumn{2}{|l|}{ 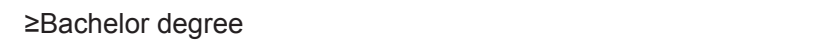 } \\
\hline \multicolumn{2}{|l|}{$<$ Bachelor degree } \\
\hline Family history of smoking & $2.342(1.396-3.928)^{*}$ \\
\hline Smoking negatively affects oral health & $0.255(0.137-0.477)^{*}$ \\
\hline Smoking is related to bad taste & $0.471(0.284-0.782)^{*}$ \\
\hline Smoking is related to bad breath & $0.276(0.159-0.480)^{*}$ \\
\hline Smoking causes oral ulcers & $0.223(0.131-0.379)^{*}$ \\
\hline Smoking causes oral cancers & $0.291(0.166-0.511)^{*}$ \\
\hline Smoking causes oral dental caries & $0.423(0.253-0.707)^{*}$ \\
\hline Smoking causes periodontal disease & $0.242(0.133-0.441)^{*}$ \\
\hline
\end{tabular}

secured higher grades had lower odds of smoking than those who had lower than $80 \%$ grades (OR: 0.261 ; CI: 0.127-0.536). On the contrary, the students with family history of smoking were 2.33 times more likely to smoke than those without family history of smoking (OR: 2.33; CI: 1.334-4.083) [Table 5].

\section{DISCUSSION}

The analysis of data in the present study shows significant findings that can be utilized to reduce 


\begin{tabular}{|c|c|}
\hline \multirow[t]{2}{*}{ Variables } & Adjusted Odds Ratio \\
\hline & OR $(95 \% \mathrm{Cl})$ \\
\hline $\begin{array}{l}\text { Academic grades }(\%) \\
>80 \\
<80\end{array}$ & $0.253(0.119-0.537)^{*}$ \\
\hline $\begin{array}{l}\text { Family income } \\
\text { Above SR14000 (Equal to US\$ 3733) } \\
\text { Below SR14000 (Equal to US\$3733) }\end{array}$ & $1.257(0.631-2.502)$ \\
\hline $\begin{array}{l}\text { Father's education } \\
\geq \text { Bachelor degree } \\
<\text { Bachelor degree }\end{array}$ & $1.034(0.577-1.856)$ \\
\hline Family history of smoking & $2.343(1.330-4.125)^{\star}$ \\
\hline Smoking negatively affects oral health & $0.433(0.194-0.965)^{*}$ \\
\hline Smoking is related to bad taste & $0.919(0.472-0.787)$ \\
\hline Smoking is related to bad breath & $0.707(0.314-1.590)$ \\
\hline Smoking causes oral ulcers & $0.414(0.201-0.50)^{\star}$ \\
\hline Smoking causes oral cancers & $0.752(0.317-1.782)$ \\
\hline Smoking causes oral dental caries & $0.842(0.419-1.692)$ \\
\hline Smoking causes periodontal disease & $0.968(0.368-2.547)$ \\
\hline
\end{tabular}

\begin{tabular}{|c|c|}
\hline Variables & OR $(95 \% \mathrm{CI})$ \\
\hline $\begin{array}{l}\text { Academic grades } \\
\text { Family income }\end{array}$ & $1.206(0.246-5.905)$ \\
\hline $\begin{array}{l}\text { Academic grades } \\
\text { Father's education }\end{array}$ & $2.059(0.345-11.995)$ \\
\hline $\begin{array}{l}\text { Smoking is related to bad taste } \\
\text { Smoking is related to bad breath }\end{array}$ & $1.563(0.337-7.243)$ \\
\hline $\begin{array}{l}\text { Smoking causes oral ulcers } \\
\text { Smoking causes oral cancers }\end{array}$ & $2.168(0.536-8.767)$ \\
\hline $\begin{array}{l}\text { Smoking causes periodontal disease } \\
\text { Smoking negatively affects oral health }\end{array}$ & $1.195(0.276-5.172)$ \\
\hline OR: Odds ratio, Cl: Confidence interval & \\
\hline
\end{tabular}

Table 5: Logistic Regression Final Model: Association between smoking and different variables

\begin{tabular}{lc}
\hline Variables & OR $(95 \% \mathrm{Cl})$ \\
\hline $\begin{array}{l}\text { Academic grades (\%) } \\
>80\end{array}$ & $0.261(0.127-0.536)^{*}$ \\
$<80$ & \\
Family history of smoking & $2.33(1.334-4.083)^{*}$ \\
Smoking negatively affects oral health & $0.342(0.167-0.699)^{*}$ \\
Smoking causes oral ulcers & $0.288(0.160-0.516)^{*}$ \\
\hline *Statistically significant, OR: Odds ratio, Cl: Confidence interval
\end{tabular}

the occurrence of smoking and improve oral health of schoolchildren. Increasing the awareness about the harmful effects of tobacco consumption on oral health should be incorporated in smoking cessations campaigns and programs. The schoolchildren who were aware of smoking effects on oral health were less likely to smoke than those who were unaware of negative consequences of smoking.

Strong epidemiological evidence has shown that smoking behavior is associated with oral complications such as oral cancers, periodontal disease, halitosis, and dental caries. ${ }^{[9]}$ It is encouraging to see vast majority of schoolchildren aware of the adverse effects of smoking, which include poor oral health, bad taste, malodor, caries, periodontal disease, oral ulcers, and oral cancers. Interestingly, awareness about the detrimental smoking effects on oral health in the present study significantly reduced the probability of smoking among schoolchildren both in univariate and multivariate analyses.

The odds of smoking were $22 \%-47 \%$ lower among adolescents who were aware of oral health consequences of smoking than those who were unaware of smoking effects. Similarly, backward stepwise final model also predicted that schoolchildren who considered that smoking can compromise the oral health and cause oral ulcers had more than $60 \%$ less chances of smoking in comparison with those who did not believe in oral complications of tobacco use. In addition, interaction analysis showed no statistically significant moderation effects on different variables while predicting odds of smoking. These findings are particularly important as children develop their lifelong oral health-related beliefs, attitudes, and behaviors during adolescence that can lead to good or poor oral health status in adulthood. ${ }^{[23,24]}$

The majority of participants were aware of smoking related oral consequences; most likely they give high importance to oral health, as maintaining proper health of oral cavity is essential to systemic health. ${ }^{[25]}$ Modest evidence exists about the link between oral conditions particularly periodontal disease with systematic diseases, such as cardiovascular disease, stroke, pulmonary disease, diabetes, adverse pregnancy outcomes and arthritis. ${ }^{[26]}$ In addition, most major oral conditions such as caries, periodontal disease, mucosal lesions, and oral cancers are irreversible; they exist for considerable time during the course of life and significantly compromise the quality of life of individuals. ${ }^{[25]}$ It is hoped that the reduction in the prevalence of smoking can be achieved by educating schoolchildren about the adverse effects of smoking on oral health together explaining the significance of oral health in relation to systematic health. 
Surprisingly, the impact of awareness of oral ulcers seem stronger than oral cancers because students who thought that smoking causes oral cancer had $\mathrm{OR}=0.75$ (CI: 0.31-1.78) compared with those who considered adverse consequences of tobacco consumption on oral ulcer OR $=0.41$ (CI: $0.20-0.50$ ). Hence, children had lower chances of smoking if they were aware of association of smoking with oral ulcers than oral cancer. This is contrary to generally accepted view that if individuals perceive the greater severity of a disease, they are more likely to change their behavior. ${ }^{[27]}$

Schoolchildren must be encouraged to quit smoking because smoking cessation is associated with the rapid reduction in tobacco related risks and can bring significant oral health benefits. ${ }^{[9]}$ For example, evidence demonstrated that quitting smoking for about 10-20 years resulted in drop of risk of oral cancers to the level of the individuals who never smoked. ${ }^{[28]}$ Schools provide opportunities to create networks and linkages among teachers, parents, and oral health professionals to develop supportive environment to achieve and maintain optimal oral health for children. ${ }^{[29]}$ That is why, oral health promotion and tobacco prevention policies and programs can best be implemented in schools. ${ }^{[29]}$

The adolescents with better academic performance in the terms of achieving higher grades had lower odds of smoking in the present study. High academic achievers had $74 \%$ less chances of smoking compared with low performing students after adjusted for other variables. These results are somewhat similar to the data available in literature. ${ }^{[30,31]}$ Pennanen et al. ${ }^{[30]}$ investigated the relationship between smoking and academic achievement and found that children who performed poor academically smoked 6 times more than those who achieved higher grades. Doku et al. . $^{[31]}$ also observed that adolescents with low academic achievement smoked 5.4 times greater compared with those who achieved better than average grades. Academically weak children were found to have positive attitudes toward smoking initiation, and were influenced greatly by their peers and had weak self-efficacy to refuse smoking. ${ }^{[32]}$ Even exposure to second hand smoke can cause poor academic performance among nonsmoking schoolchildren. ${ }^{[33]}$

According to the $\mathrm{WHO}$, interrelation exists between poverty and smoking. Low income individuals were found to smoke more than high income counterparts and smoking exacerbated poverty ${ }^{[34]}$ Nevertheless, the results of present study do not lend support to such an association. Our results showed that children from high income families had $25 \%$ more chances of smoking in comparison with adolescents with low household income. The argument of economic advantage with high family income seems to provide explanation of slightly higher probability of smoking among children as they can afford to purchase more cigarettes than children from low-income class.

Literature documented that the existence of tobacco use among parents, sibling and immediate relatives can cause adolescents to initiate smoking. ${ }^{[35,36]}$ The influence of family members on children's smoking behavior was the most important predictor as $65.9 \%$ of children were found to smoke if there was a smoker at home. ${ }^{[35]}$ Similarly, Jarvis et al. demonstrated higher concentration of cotinine in saliva of children of smoker parents, thus reflecting the major impact of parental smoking on children. ${ }^{[36]}$ The results of the present study are in accordance with the available evidence as schoolchildren with family history of smoking were 2.34 times more likely to smoke than those without family history of smoking.

Methodological quality standards were maintained during all stages of the present research and steps taken to ensure validity of the results. However, there are four limitations about the data presented in the current study. First, only male adolescents participated in the study due to some cultural limitations. Second, participants were recruited from public schools and private schools were not contacted as more affluent children usually attend private schools and their participation in the study could influence the results. Third, Dammam is a metropolitan city and inclusion of participants from such geographic location might reflect different results than if children from small towns or remote areas were included in the study. Therefore, application of the results of the study to female schoolchildren and adolescents from geographically remote locations should be carried out with certain level of carefulness. Fourth, cross-sectional study design has its own limitations regarding inference of cause and effect. ${ }^{[37]}$ Future studies should employ prospective cohort study design when evaluating an association between awareness of smoking effects on oral health and likelihood of smoking in schoolchildren.

\section{CONCLUSIONS}

The findings of the study suggest that schoolchildren with raised awareness of smoking effects on oral health 
were less likely to smoke. The adolescents who believed that tobacco consumption can adversely affect their oral health had lower probability of smoking than those who were not aware of the negative consequences of tobacco use on oral tissues. The results of our study also show that attaining higher academic scores can help students devote more time to their studies and avoid smoking behaviors. Moreover, smoking patterns among family members increase the probability of smoking in children. Improving the academic environment in schools can further help reduce tobacco use among adolescents and minimize its economic burden on the society.

Saudi Arabia has a national tobacco control program that aims at evaluating the prevalence of smoking and its adverse health effects including economic impact, and preventing the epidemic of smoking complications. In addition, there are policies about controlling smoking in educational institutions, health-care facilities, public transportation, and banning tobacco commercial advertisements.

It is suggested that antismoking policies aimed at enforcing the control of tobacco use and improving oral and systemic health should consider the support of family members particularly parents. Supportive environment for developing healthy life styles among children should be created utilizing possibilities of interaction among teachers, parents, and health-care providers in schools. Educating students about the complications of smoking on oral health should be the part of smoking cessation programs and policies. Future research should evaluate if the effects of tobacco use lead students to perform poorly at schools. Moreover, to reduce smoking related health inequalities among schoolchildren, the role of academic achievement should be investigated in future studies.

\section{Financial support and sponsorship}

Nil.

\section{Conflicts of interest}

There are no conflicts of interest.

\section{REFERENCES}

1. World Health Organization. WHO Global Report on Trends in Tobacco Smoking 2000-2025. Available from: http://www.who.int/tobacco/ publications/surveillance/reportontrendstobaccosmoking/en/. [Last cited on 2016 Sep 12].

2. Rentería E, Jha P, Forman D, Soerjomataram I. The impact of cigarette smoking on life expectancy between 1980 and 2010: A global perspective. Tob Control 2016;25:551-7.

3. World Health Organization. Tobacco Free Initiative (TFI). Tobacco Control Economics. Available from: http://www.who.int/tobacco/ economics/en/. [Last cited on 2016 Sep 12].
4. Csikar J, Kang J, Wyborn C, Dyer TA, Marshman Z, Godson J. The self-reported oral health status and dental attendance of smokers and non-smokers in England. PLoS One 2016;11:e0148700.

5. Chung CW, Wang JD, Yu CF, Yang MC. Lifetime medical expenditure and life expectancy lost attributable to smoking through major smoking related diseases in Taiwan. Tob Control 2007;16:394-9.

6. Hoang Anh PT, Thu le T, Ross H, Quynh Anh N, Linh BN, Minh NT. Direct and indirect costs of smoking in Vietnam. Tob Control 2016;25:96-100.

7. Ekpu VU, Brown AK. The economic impact of smoking and of reducing smoking prevalence: Review of evidence. Tob Use Insights 2015;8:1-35.

8. Salama R. Challenges facing smokers in Saudi Arabia. Int J Health Sci (Qassim) 2012;6:V-VI.

9. Warnakulasuriya $S$, Dietrich $T$, Bornstein MM, Casals Peidró E, Preshaw PM, Walter C, et al. Oral health risks of tobacco use and effects of cessation. Int Dent J 2010;60:7-30.

10. Jha P, Ramasundarahettige C, Landsman V, Rostron B, Thun M,

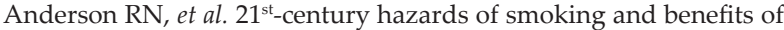
cessation in the United States. N Engl J Med 2013;368:341-50.

11. Pirie K, Peto R, Reeves GK, Green J, Beral V; Million Women Study Collaborators. The $21^{\text {st }}$ century hazards of smoking and benefits of stopping: A prospective study of one million women in the UK. Lancet 2013;381:133-41.

12. Towns S, DiFranza JR, Jayasuriya G, Marshall T, Shah S. Smoking cessation in adolescents: Targeted approaches that work. Paediatr Respir Rev 2015. pii: S1526-054200039-1.

13. Singh T, Arrazola RA, Corey CG, Husten CG, Neff LJ, Homa DM, et al. Tobacco use among middle and high school students - United States, 2011-2015. MMWR Morb Mortal Wkly Rep 2016;65:361-7.

14. U.S. Department of Health and Human Services. The Health Consequences of Smoking - 50 Years of Progress: A Report of the Surgeon General. Atlanta: U.S. Department of Health and Human Services, Centers for Disease Control and Prevention, National Center for Chronic Disease Prevention and Health Promotion, Office on Smoking and Health. Available from: http://www.surgeongeneral. gov/library/reports/50-years-of-progress/?_ga=1.85329114.25221780 1.1464102713.\#execsumm. [Last cited on 2016 Sep 13].

15. Hanewinkel R, Isensee B, Sargent JD, Morgenstern M. Cigarette advertising and teen smoking initiation. Pediatrics 2011;127:e271-8.

16. O'Loughlin J, Karp I, Koulis T, Paradis G, Difranza J. Determinants of first puff and daily cigarette smoking in adolescents. Am J Epidemiol 2009;170:585-97.

17. Park HK, Al Agili DE, Bartolucci A. Factors affecting tobacco use among middle school students in Saudi Arabia. Matern Child Health J 2012;16:1828-36.

18. Aryal UR, Petzold M, Krettek A. Perceived risks and benefits of cigarette smoking among Nepalese adolescents: A population-based cross-sectional study. BMC Public Health 2013;13:187.

19. Song AV, Morrell HE, Cornell JL, Ramos ME, Biehl M, Kropp RY, et al. Perceptions of smoking-related risks and benefits as predictors of adolescent smoking initiation. Am J Public Health 2009;99:487-92.

20. Al-Qurashi H, Al-Farea M, Al-Qurai T, Al-Kadi M, Al-Bassam B, Nazir MA. Comparison of oral hygiene practices and oral health problems among smoker and non-smoker male adolescents in the Eastern Province of Saudi Arabia. Saudi J Dent Res 2016;7:106-11.

21. Schaeffer RL, Mendenhall W, Ott L. Elementary Survey Sampling. $4^{\text {th }}$ ed. Belmont, California: Duxbury Press; 1990.

22. Reed $\mathrm{P}, \mathrm{Wu} \mathrm{Y}$. Logistic regression for risk factor modelling in stuttering research. J Fluency Disord 2013;38:88-101.

23. Broadbent JM, Thomson WM, Poulton R. Oral health beliefs in adolescence and oral health in young adulthood. J Dent Res 2006;85:339-43

24. Broadbent JM, Zeng J, Foster Page LA, Baker SR, Ramrakha S, Thomson WM. Oral health-related beliefs, behaviors, and outcomes through the life course. J Dent Res 2016;95:808-13.

25. World Health Organization. The World Health Report 2003. Continuous Improvement of Oral Health in the $21^{\text {st }}$ Century - The Approach of the WHO Global Oral Health Programme. Available from: http://www.who.int/oral_health/media/en/orh_report03 en.pdf. [Last cited on 2016 Jul 03].

26. Linden GJ, Herzberg MC; Working Group of the Joint EFP/AAP Workshop. Periodontitis and systemic diseases: A record of discussions 


\section{Nazir and Almas: Oral complications and smoking in adolescents}

of working group 4 of the joint EFP/AAP workshop on periodontitis and systemic diseases. J Periodontol 2013;84 4 Suppl: S20-3.

27. Kasmaei P, Amin Shokravi F, Hidarnia A, Hajizadeh E, Atrkar-Roushan Z, Karimzadeh Shirazi K, et al. Brushing behavior among young adolescents: Does perceived severity matter. BMC Public Health 2014;14:8.

28. Marron M, Boffetta P, Zhang ZF, Zaridze D, Wünsch-Filho V, Winn DM, et al. Cessation of alcohol drinking, tobacco smoking and the reversal of head and neck cancer risk. Int J Epidemiol 2010;39:182-96.

29. World Health Organization. Oral Health. Important Target Groups. Available from: http://www.who.int/oral_health/action/groups/ en/. [Last cited on 2016 Jun 13].

30. Pennanen M, Haukkala A, de Vries H, Vartiainen E. Longitudinal study of relations between school achievement and smoking behavior among secondary school students in Finland: Results of the ESFA study. Subst Use Misuse 2011;46:569-79.

31. Doku D, Koivusilta L, Rainio S, Rimpelä A. Socioeconomic differences in smoking among Finnish adolescents from 1977 to 2007. J Adolesc
Health 2010;47:479-87.

32. Pennanen M, Haukkala A, De Vries H, Vartiainen E. Academic achievement and smoking: Is self-efficacy an important factor in understanding social inequalities in Finnish adolescents? Scand J Public Health 2011;39:714-22.

33. Ho SY, Lai HK, Wang MP, Lam TH. Exposure to secondhand smoke and academic performance in non-smoking adolescents. J Pediatr 2010;157:1012-7.e1.

34. World Health Organization. Tobacco Free Initiative (TFI). Available from: http://www.who.int/tobacco/research/economics/rationale/ poverty/en/. [Last cited on 2016 Jun 27].

35. Fida HR, Abdelmoneim I. Prevalence of smoking among male secondary school students in Jeddah, Saudi Arabia. J Family Community Med 2013;20:168-72.

36. Jarvis MJ, Goddard E, Higgins V, Feyerabend C, Bryant A, Cook DG. Children's exposure to passive smoking in England since the 1980s: Cotinine evidence from population surveys. BMJ 2000;321:343-5.

37. Levin KA. Study design III: Cross-sectional studies. Evid Based Dent 2006;7:24-5. 